\title{
A comparison of manual vacuum aspiration with medical method of abortion in termination of pregnancy up to 9 weeks of gestational age
}

\author{
Pramod Garhwal*, Lata Rajoria, Manju Sharma
}

Department of Obstetrics and Gynecology, SMS Medical College, Jaipur, Rajasthan, India

Received: 17 July 2017

Accepted: 22 July 2017

\section{*Correspondence:}

Dr. Pramod Garhwal,

E-mail: pramodgarhwal45@gmail.com

Copyright: () the author(s), publisher and licensee Medip Academy. This is an open-access article distributed under the terms of the Creative Commons Attribution Non-Commercial License, which permits unrestricted non-commercial use, distribution, and reproduction in any medium, provided the original work is properly cited.

\section{ABSTRACT}

Background: Objective of present study was to compare efficacy and complications of medical method versus manual vacuum aspiration in early pregnancy termination and to determine whether medical method of termination of pregnancy represent a reasonable alternative to surgical method (MVA) in terms of complete evacuation of products of conception and their side effects.

Methods: A comparative study was carried out on 184 pregnancies in women who were willing for termination of pregnancy up to 9 weeks (63 days) of gestational age, in Group A: women who opted for medical method for termination, Group B: women who opted for manual vacuum aspiration for termination.

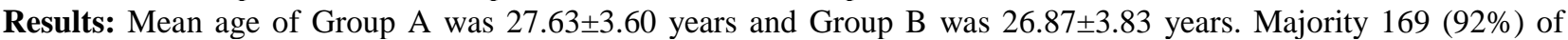
women were Hindu. $165(90 \%)$ of the patients lived in urban area and $176(96 \%)$ were married women. Majority 130 (71\%) of them were para 2 and more. Average age of gestation at which termination was performed was $46.79 \pm 6.29$ days in Group A and 49.13 \pm 6.67 days in Group B. Average duration of vaginal bleeding among Group A was found to be $8.9 \pm 3.5$ days ( $p$ value $<0.05$ ) and in Group B was $6.837+2.928$ days which was significantly longer in Group A. $72(78.3 \%)$ patients considered vaginal bleeding to be heavier than their normal period in Group A where as in Group B $8(8.7 \%)$ perceived it to be heavier ( $\mathrm{p}$ value $<0.001$ ). Incidence of pain, nausea, vomiting, diarrhea and incomplete abortion $(78.26 \%, 32.60 \%, 16.3 \%, 19.56 \%$ and $4.43 \%)$ in group $\mathrm{A}$ and $(52 \%, 7.6 \%, 4.3 \%$, nil and $2.17 \%)$ in group B which were found to be higher in Group A as compare to Group B. Patient satisfaction was $95.65 \%$ in medical method and $84.78 \%$ in MVA group. Success rate was $95.65 \%$ for medical and $97.82 \%$ for MVA group.

Conclusions: Duration and amount of bleeding per vaginum is more in medical method as compare to surgical method. Side effects like pain, nausea, vomiting and diarrhea were more in medical group, but majority of these symptoms were self-limiting. There was high satisfaction rate $(95.65 \%)$ among medical abortion group because less surgical and anaesthetic complication, offer them more privacy and treatment is taken at home. The effectiveness of medical method of abortion in present study was $95.65 \%$ and success rate in MVA was $97.82 \%$. Medical method of abortion for first trimester termination of pregnancy upto 9 weeks of gestation can be better alternative method to surgical evacuation. Medical method of abortion proves to be more effective, safe and economical method that avoid complication associated with surgical evacuation like uterine perforation, cervical laceration and anaesthtic complication. The only disadvantage with medical method of abortion is lack of predictability and variable success rate.

Keywords: Abortion, Manual vacuum aspiration, Misoprostol, Mifepristone 


\section{INTRODUCTION}

Every year millions of women are exposed to unprotected intercourse or face failure of contraceptive methods involving risk of unwanted pregnancy. Termination of such unwanted pregnancies are adequately covered by protective umbrella of MTP ACT 1971, with its amendment No -64 (19 Dec 2002). The overall risk of death from legal abortion is less than 1 per 100000 . But even after 42 years of legalization of voluntary termination of pregnancy (MTP) in India, its availability, particularly in rural area is very limited. As a result, 15,000 to 20,000 abortion related deaths are reported in india every year out of which $8 \%$ are due to unsafe abortion which is serious concern. ${ }^{1}$ There is an unmet need for an easily available method of early pregnancy termination which is both safe and effective. Two methods which fulfil this need are medical method of abortion using mifeprostone and misoprostol and surgical abortion with manual vacuum aspiration.

\section{METHODS}

This is a prospective comparative study conducted in Department of Obstetrics and Gynecology SMS Medical College, Jaipur (Rajasthan) from March 2015 October 2016.A total number of 184 cases, up to 9 weeks of gestation and willing for termination were included in the study. After taking informed and written consent Study population was divided into two groups according to women's desire.

- Group A: women who opted for medical method for termination

- Group B: women who opted for manual vacuum aspiration for termination.

\section{Inclusion criteria}

Pregnant women with 9 weeks (63 days) of gestation, irrespective of parity who were willing for termination of pregnancy (MTP criteria should be fulfilled).

\section{Exclusion criteria}

- Anemia $\mathrm{Hb}<8 \mathrm{gm} \%$

- Gestation $>9$ weeks

- Ectopic pregnancy

- Molar pregnancy

- Uterine anomalies

- Pelvic infection

- Bleeding disorders

- Maternal history of asthma or cardiac disease

- Known maternal allergy to prostaglandins or previous adverse reaction

In all selected cases menstrual, contraceptive, obstetric, medical and surgical history was taken. Clinical examination including general physical and systemic examination was done.

Bimanual Pelvic examination was done to know the position, size and mobility of uterus the presence of infection.

The haematological investigation included like CBC, blood grouping and Rh typing, Blood sugar level and urine routine microscopy was done. Ultrasonography was done.

\section{Medical method}

After confirming gestational age by ultrasound, and after written informed consent. Following regimen was followed. All norms as per the MTP act by the government of india were followed. On first day of medical abortion mifepristone $200 \mathrm{mg}$ was given orally. The patient was asked to keep tab. Misoprost 800ug per vaginally after $48 \mathrm{hrs}$ at home, schedule was completed even if the woman aborted with mifepristone only. women were asked to note onset of bleeding, timing of passage of product of Conception, duration of bleeding and side effects. Inj Anti D 300ug given within $72 \mathrm{hrs}$ of abortion in $\mathrm{Rh}$ negative blood group women. Women were called or follow-up after 14 day and clinical evaluation was done. Ultrasound was done if patient with excessive bleeding. Success was defined as complete expulsion of products of conception with no need for surgical intervention.

\section{MVA}

MVA was done by $60 \mathrm{ml}$ manual vacuum aspiration double valved syring. The uterine contents aspirated were taken on a gauze piece and examined to identify gestational sac. $^{2}$

\section{RESULTS}

Mean age - In Group A $=27.63 \pm 3.60$ years and In Group $\mathrm{B}=26.87 \pm 3.83$ years. which is comparable to a study by Rita G Nayak et al, Banerjee et al and Shetty et al where mean age group of patients was $26 \pm 2.42,27 \pm 4.2$ and $29.8 \pm 4.4$ respectively. ${ }^{2-4}$

Table 1: Distribution of patients according to age.

\begin{tabular}{|c|c|c|c|c|c|}
\hline Age & \multicolumn{2}{|c|}{ Group A } & \multicolumn{2}{|c|}{ Group B } & P value \\
\hline & $\mathbf{N}$ & $\%$ & $\mathbf{N}$ & $\%$ & \multirow{6}{*}{0.75} \\
\hline$-<20$ & 2 & 2.1739 & - & - & \\
\hline $21-25$ & 26 & 28.26 & 39 & 42.3913 & \\
\hline $26-30$ & 56 & 60.86 & 40 & 43.4782 & \\
\hline $31-35$ & 7 & 7.60 & 11 & 11.9565 & \\
\hline $36-40$ & 1 & 1.08 & 2 & 2.1739 & \\
\hline
\end{tabular}

The above Table 2 shows most of cases coming for MTP belonged to urban area. In group A $82(89.13 \%)$ and in group B $83(90.22 \%)$ people reside in urban area. 
Table 2: Distribution of patients according to residence.

\begin{tabular}{|c|c|c|c|c|c|}
\hline Residence & \multicolumn{2}{|c|}{ Group A } & \multicolumn{2}{|c|}{ Group B } & P Value \\
\hline & $\mathbf{N}$ & $\%$ & $\mathbf{N}$ & $\%$ & \\
\hline Rural & 10 & 10.87 & 9 & 9.78 & 0.809 \\
\hline Urban & 82 & 89.13 & 83 & 90.22 & \\
\hline
\end{tabular}

Table 3: Distribution of patients according to marital status.

\begin{tabular}{|lllll|}
\hline Marital status & \multicolumn{2}{c}{ Group - A } & \multicolumn{2}{c|}{ Group - B } \\
\hline Married & N & \% & N & \% \\
\hline Unmarried & 85 & 92.39 & 91 & 98.92 \\
\hline Widow & 4 & 4.35 & 0 & 0.00 \\
\hline Separated & 2 & 2.17 & 0 & 0.00 \\
\hline p value $=0.102$ & 1 & 1.09 & 1 & 1.09 \\
\hline
\end{tabular}

Table 3 shows that majority of patients were married 176 $(95.65 \%)$. In group A $85(92.39 \%)$ cases and in group B $91(98.91 \%)$ were married. There were 4 patients who were unmarried and all opted for medical termination.

Table 4: Distribution of patients according to parity.

\begin{tabular}{|lllll|}
\hline Parity & \multicolumn{2}{l}{ Group-A } & \multicolumn{2}{l|}{ Group-B } \\
\hline & N & \% & N & \% \\
\hline Nullipara & 7 & 7.60 & 2 & 2.17 \\
\hline Para 1 & 24 & 26.08 & 21 & 22.82 \\
\hline Para 2 & 39 & 42.39 & 28 & 30.43 \\
\hline Para >3 & 22 & 23.91 & 41 & 44.56 \\
\hline Total & 92 & 99.9999 & 92 & 99.9998 \\
\hline
\end{tabular}

$45(24.45 \%)$ patients were Para 1, $67(36.41 \%)$ were para 2 and $63(34.23 \%)$ were belonging to higher parity. Overall $9(4.89 \%)$ patients were nulliparas and most of them $(77.77 \%)$ opted for medical method of termination ( $p$ value $<0.05$ ) which is statistically significant showing more inclination of nulliparous women towards noninvasive procedure.
Table 5: Distribution of cases according to gestation age.

\begin{tabular}{|lllll|}
\hline Gestation age & \multicolumn{2}{c}{ Group-A } & \multicolumn{2}{c|}{ Group-B } \\
\hline Days & N & \% & N & \% \\
\hline$<42$ & 29 & 31.52 & 15 & 17.39 \\
\hline $43-49$ & 39 & 42.39 & 43 & 46.73 \\
\hline $50-56$ & 16 & 17.39 & 22 & 23.91 \\
\hline $57-63$ & 8 & 8.69 & 12 & 13.04 \\
\hline p value $=0.094$ & & & & \\
\hline
\end{tabular}

Average gestational age in Group $\mathrm{A}=46.79 \pm 6.29$ days and Group B $=49.13 \pm 6.67$ days (6-7weeks), $44 \%$ of patients belongs to this gestational age which was comparable to a study by Nayak R et al in which $41 \%$ of patients belonged to 6-7 weeks (mean age) and study by Mundle et al in which $40 \%$ patient belonged to 6-7 weeks and mean age was 45 days in a study by Platais I et al.,5,6

Table 6: Distribution of patients according to duration of bleeding per vaginum.

\begin{tabular}{|c|c|c|c|c|c|}
\hline $\begin{array}{l}\text { Duration of } \\
\text { bleeding }\end{array}$ & \multicolumn{2}{|c|}{ Group A } & \multicolumn{2}{|c|}{ Group B } & p value \\
\hline Days & $\mathbf{N}$ & $\%$ & $\mathbf{N}$ & $\%$ & \multirow{5}{*}{$<0.001$} \\
\hline $1-4$ & 8 & 8.69 & 58 & 63.04 & \\
\hline $5-9$ & 58 & 63.04 & 28 & 30.43 & \\
\hline $10-14$ & 22 & 23.91 & 4 & 4.34 & \\
\hline$>14$ & 4 & 4.34 & 2 & 2.2 & \\
\hline
\end{tabular}

Average duration of bleeding P.V. in Group A = $8.924 \pm 3.568$ days and Group $\mathrm{B}=6.837 \pm 2.928$ days. Amount and duration of bleeding per vaginum were found to be more in Group A because spontaneous expulsion of the products of conceptus takes a long time and heavy bleeding persist during this period.

In a study by Davis A et al found that medical abortion group had a mean of 14 days bleeding which was higher than the MVA group mean of 9 days.

Table 7: Distribution of patients according to common side effects and complications in two groups.

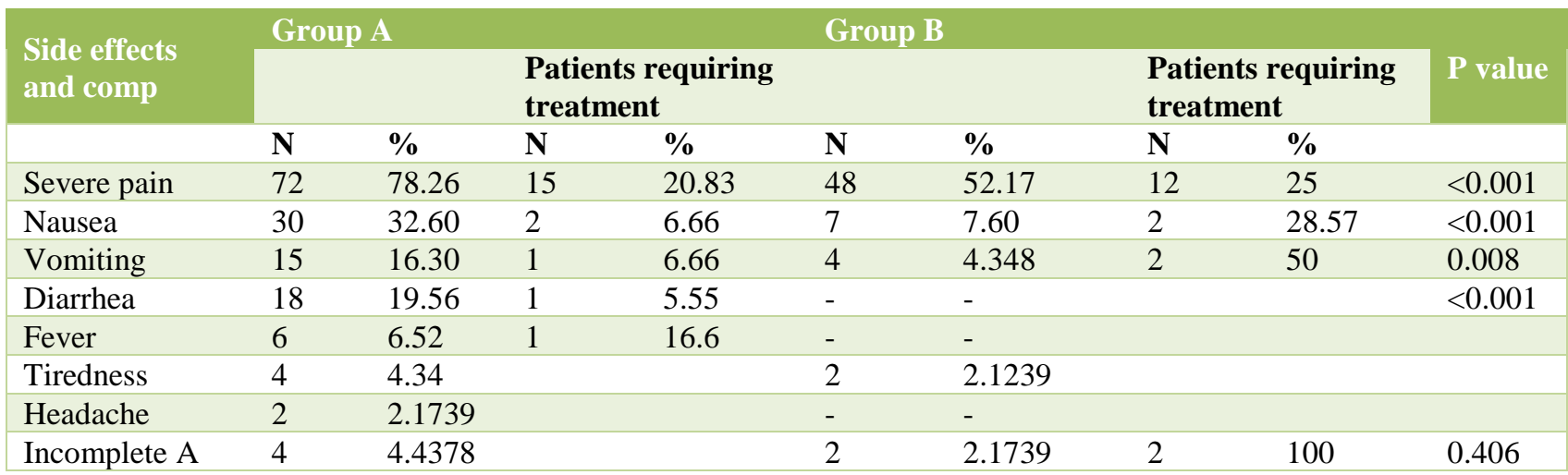


Severe pain and gastrointestinal symptoms like nausea, vomiting and diarrhoea were more in group A $(78.26 \%$, $32.60 \%, 16.30 \%$ and $19.56 \%$ ) as compare to group B $(52.17 \%, 7.60 \%, 4.34 \%$ and nil). $4(4.4 \%)$ cases of group $\mathrm{A}$ and $2(2.17 \%)$ cases of group B had incomplete abortion and required recurettage. According to Nayak RG et al Participants did not experience any serious complications. $^{2}$ All women $(100 \%)$ reported at least some bleeding, out of these $2.4 \%$ patients had heavy bleeding but blood transfusion was not required. $6.02 \%$ patients had vomiting and $2.40 \%$ had fever and $2.40 \%$ had incomplete abortion in medical method of abortion. Only One case of uterine perforation was noted in group B. In the WHO study lower, abdominal pain was reported in $82.8 \%$, nausea in $53.2 \%$, vomiting in $20.5 \%$ and diarrhoea in $8.6 \%$ of medical abortion cases. ${ }^{7}$ A study by Vinita D et al found that in the case of medical abortion, lower abdominal pain was the most common side effect reported in $80 \%$ of the cases, followed by nausea $(56.67 \%)$, vomiting $(16.67 \%)$ and diarrhoea $(10 \%){ }^{8}$ Present finding confirm this.

Table 8: Distribution of patients according to outcome of procedure.

\begin{tabular}{|lllll|}
\hline $\begin{array}{l}\text { Outcome of } \\
\text { procedure }\end{array}$ & Group A & \multicolumn{2}{l|}{ Group B } \\
\hline & N & \% & N & \% \\
\hline Success & 88 & 95.65 & 90 & 97.82 \\
\hline failure & 4 & 4.34 & 2 & 2.17 \\
\hline
\end{tabular}

Medical abortion procedure was $95.65 \%$ successful, with failure rate of $4.34 \%$ due to incomplete abortion which was managed by surgical curettage. In group B had success rate of $97.82 \%$ and 2 had incomplete abortion required recurettage. The effectiveness of medical method of abortion in present study was $95.65 \%$ and success rate of MVA was $97.82 \%$ which was comparable to a study done by Nayak RG et al effectiveness of medical method of abortion was $97.6 \%$ and in MVA was $100 \%$, Vinita D et al success rate of medical method was $96.67 \%$ and in MVA was $96.91 \%$, Zhang $\mathrm{J}$ et al success rate of medical method was $84 \%$ and $97 \%$ in surgical group and Rorbye $\mathrm{C}$ et al success rate of medical method and MVA was $94.1 \%$ vs $97.7 \% .^{2,8-10}$

\section{DISCUSSION}

Mean age - In Group A $=27.63 \pm 3.60$ years and In Group $\mathrm{B}=26.87 \pm 3.83$ years. which is comparable to a study by Rita G Nayak et al, Banerjee et al and Shetty et al where mean age group of patients was $26 \pm 2.42,27 \pm 4.2$ and $29.8 \pm 4.4$ respectively. ${ }^{2-4}$ Majority of patients were married $176(95.65 \%)$. In group A $85(92.39 \%)$ cases and in group B $91(98.91 \%)$ were married. Average gestational age in Group $A=46.79 \pm 6.29$ days and Group $\mathrm{B}=49.13 \pm 6.67$ days $(6-7$ weeks $), 44 \%$ of patients belongs to this gestational age which was comparable to a study by Nayak $\mathrm{R}$ et al in which $41 \%$ of patients belonged to 6-7 weeks (mean age) and study by Mundle et al in which $40 \%$ patient belonged to 6-7 weeks and mean age was 45 days in a study by Ingrida Platais et al. $^{2,5,6}$ Average duration of bleeding P.V. in Group A = $8.924 \pm 3.568$ days and Group $\mathrm{B}=6.837 \pm 2.928$ days. Amount and duration of bleeding per vaginum were found to be more in Group A. In a study by Davis A et al found that medical abortion group had a mean of 14 days bleeding which was higher than the MVA group mean of 9 days.

The effectiveness of medical method of abortion in present study was $95.65 \%$ and success rate of MVA was $97.82 \%$ in my study which was comparable to a study done by Nayak RG et al effectiveness of medical method of abortion was $97.6 \%$ and in MVA was $100 \%$, Vinita D et al success rate of medical method was $96.67 \%$ and in MVA was $96.91 \%$, Zhang $\mathrm{J}$ et al success rate of medical method was $84 \%$ and $97 \%$ in surgical group and Rorbye $\mathrm{C}$ et al success rate of medical method and MVA was $94.1 \%$ vs $97.7 \% .^{2,8-10}$

\section{CONCLUSION}

Thus, we conclude that duration and amount of bleeding per vaginum is more in medical method as compare to surgical method. Side effects like pain, nausea, vomiting and diarrhea were more in medical group, but majority of these symptoms were self-limiting. There was high satisfaction rate $(95.65 \%)$ among women who underwent a non-operative procedure (medical method) because less surgical and anaesthetic complication, offer them more privacy and treatment is taken at home. The effectiveness of medical method of abortion in present study was $95.65 \%$ and success rate in MVA was $97.82 \%$. Medical method of abortion for first trimester termination of pregnancy upto 9 weeks of gestation can be better alternative method to surgical evacuation.

\section{Funding: No funding sources \\ Conflict of interest: None declared}

Ethical approval: The study was approved by the Institutional Ethics Committee

\section{REFERENCES}

1. WHO unsafe abortion: Global and regional estimates of the incidence of unsafe abortion and associated mortality in 2003. $5^{\text {th }}$ ed. WHO;2007:14.

2. Nayak RG, Patil YS, Patil SK, NK. A Comparison of manula vaccum aspiration with medical method of abortion in termination of pregnancy upto 9 weeks of gestational age. Int $\mathbf{J}$ Recent Trends Sci Tech. 2015;13(3): 490-4.

3. Banerjee A, Abhijit A, Batya E, Kalyanwala S. Mifepristone and misoprostol abortion in free standing. Reproductive health clinic in India. J Obstet Gynecol India. 2009;59(5):432-9.

4. Shetty J, Pallavi MNV. Medical Abortion by Mifepristone with oral versus vaginal misoprostol. J Obstet Gynecol India. 2006;56(6):529-531. 
5. Shuchita M, Shveta K, Batya E, Suresh U. Simplifying medical abortion: home administration of misoprostol. J obstat Gynecol India 2008;58(5)410-6.

6. Platais I, Tsereteli T, Grebennikova G, Lotarevich T, Winikoff B. Prospective study of home use of mifepristone and misoprostol for medical abortion up to 10 weeks of pregnancy in Kazakhstan. Int $\mathbf{J}$ Gynecol Obstet. 2016;134(3):268-71.

7. Von Hertzen $\mathrm{H}, \mathrm{Wu} \mathrm{YM}$, GomezAlzugaray M, Haukkamaa M, Ngoc NT, Ho PC et al. Comparison of two doses of mifeprostone is combination with misoprostol for early medical abortion a randomized trial world health organization task face on post ovulatory methods of fertility regulation. BJOG 2000;107:524-30.

8. Das V, Jain S, Gupta HP, Agarwal A, Sujata, Pandey A. Evaluation of newer methods of early pregnancy termination. J Obst Gynecol India. 2005;55(5):454-6.
9. Zhang J, Gilles JM, Barnhart K, Creinin MD, Westhoff C, Frederick MM. A comparison of medical management with misoprostol and surgical management for early pregnancy failure. $\mathrm{N}$ Engl $\mathbf{J}$ Med. 2005;353(8):761-9.

10. Rørbye C, Nørgaard M, Nilas L. Medical versus surgical abortion: comparing satisfaction and potential confounders in a partly randomized study. Human Reprod. 2005;20(3):834-8.

Cite this article as: Garhwal P, Rajoria L, Sharma M. A comparison of manual vacuum aspiration with medical method of abortion in termination of pregnancy up to 9 weeks of gestational age. Int $\mathbf{J}$ Reprod Contracept Obstet Gynecol 2017;6:3813-7. 